\title{
Job performance in chronic hepatitis $C$ virus patients treated with pegylated interferon- $a 2 b$ plus ribavirin: an observational study
}

Giulia Malaguarnera ${ }^{1,2^{*}}$, Gaetano Bertino ${ }^{3}$, Carmela Greco ${ }^{2}$, Caterina Gagliano ${ }^{4,5}$, Massimo Motta², Giuseppe Chisari ${ }^{1}$, Venerando Rapisarda ${ }^{6}$, Giuseppe Nunnari ${ }^{7}$, Michele Vecchio ${ }^{8}$, Filippo Drago ${ }^{1}$ and Michele Malaguarnera ${ }^{1,2}$

\begin{abstract}
Background: The employment status of workers with chronic hepatitis $C$ has important implications for society and labor market, for organizations and for the individuals and their economic, social and psychological status. To evaluate the effects to Peg-IFN-a and RBV treatment on work ability (WAI) and perceived on work stress (PWS). One hundred forty-four patients consecutive with chronic hepatitis $C$ had been enrolled and treated with Pegylated-Interferon- $\mathrm{a} 2 \mathrm{~b}$ at dose $1.5 \mathrm{mg} / \mathrm{kg}$ per week plus daily oral Ribavirin for 12 months. The work ability (WA) and perceived work stress (PWS) were evaluated. The baseline value of PWS and WAI were compared to the values obtained at end of months 1, 3, 6, 12 and at follow up. At the end of the study we have also compared the following groups: pretreatment, end treatment response (ETR), sustained response, no response, and relapse.
\end{abstract}

Results: The comparison between end treatment response (ETR) and sustained viral response (SVR) showed a significant difference in PWS. Comparison between ETR and both non responders (NR) and relapser showed significant differences in perceived work stress $p<0.01$ and work ability index $p<0.05$.

Conclusions: HCV workers, treated with Peg-IFNa 2b plus Ribavirin, shows work performance loss, a decrease of work ability at 1 month and increase in work ability in patients with end on treatment response and in sustained responders decrease in perceived work stress.

Trial registration: This is not a registered study as an observational study. We measured the job performance in subjects who was undergoing to the gold standard therapy for Hepatitis $C$ at the moment of our evaluation.

Keywords: Interferon, Ribavirin, Hepatitis C, Fatigue, Work

\footnotetext{
* Correspondence: giulia.malaguarnera@live.it

${ }^{1}$ Department of Biomedical and Biotechnological Sciences, School of

Medicine, University of Catania, 95125 Catania, Italy

${ }^{2}$ Research Center "The Great Senescence", University of Catania, Catania, Italy

Full list of author information is available at the end of the article
} 


\section{Background}

Chronic hepatitis $\mathrm{C}$ virus (HCV) infection is a worldwide public health problem with a global prevalence of $2 \%$ [1]. According to some estimates, 3-4 million people are newly infected every year worldwide and 350.000 patients die every year dye to HCV-related disorders. If left untreated, chronic $\mathrm{HCV}$ infection puts patients at increased risk for cirrhosis, and hepatocellular carcinoma [2-4]. Rates of sustained virologic response with Peg Interferon- Ribavirin therapy remain below $50 \%$ and are after less than $30 \%$ among patients who have HCV genotype 1 infection and certain baseline characteristics, such as advanced fibrosis, diabetes, depression and co- infections [5]. There has been recent interest in the mechanisms by which psychological stress can translate into immune system activation and release of proinflammatory cytokines $[6,7]$. Patients with hepatitis $C$ are stigmatized in society and stigmatization was associated with increased anxiety, loss of control and difficult coping [8]. Fatigue, malaise, concentration difficulties, depression, stress and related negative moods prevail in the HCV population and may represent barriers to treatment with combination therapy. There is growing interest in the iatrogenic depression that results from exogenous interferon- alpha (IFN- $\alpha$ ) therapy [8-10]. Depression, anxiety and fatigue are among the most common adverse events in IFN/ribavirin treatment and their cumulative incidence seems to increase during IFN treatment, but returns to baseline values following completion of therapy [11]. Research in community based population documents that depression has an adverse affect on employment, resulting in job loss, absenteeism and reduced at work job performance and productivity $[12,13]$. Despite some advances in the treatment of $\mathrm{HCV}$, interferon is still a component of therapy. To fully characterize the impact of HCV and the burden of disease progression, the negative effects of both HCV and IFN treatment on worker productivity and lifestyle impairment need to be understood [14-17]. Work plays an important role in the wellbeing for many HCV patients; in fact the level of satisfaction at work was often as a strong motivator of social status and for social contacts. Work stress may have negative impact for both job performance and quality of life.

The aim of the study is to evaluate effects of PegIFN and Ribavirin when being at work and treating the disease. The purpose is also to evaluate the negative side effects the treatment brings, measuring perceived work stress (PWS) and work ability (WA) experienced by patients with Peg-IFN-a plus ribavirin, according to the response treatment. Such data can also be used to identify the real costs and benefits of treating $\mathrm{HCV}$ patients and preventing disease progression.

\section{Methods}

\section{Study design}

This 12 months, observational study was performed in accordance with the principles of the World Medical Association Declaration of Helsinki (1997) [18] and was approved by the local Ethics Committee. It was conducted in the Department of Internal Medicine of Cannizzaro Hospital, University of Catania, Catania, Italy. A medical interview and a physical examination were realized for all patients included in the study before starting therapy. All the study was designed as a prospective longitudinal single-center study. All enrolled patients were included in the intention-to-treat efficacy analysis and patients who received at least one dose of Peg-IFN- $\alpha 2 \mathrm{~b}(1.5 \mathrm{mg} /$ $\mathrm{kg}$ per week) plus daily oral RBV were included in the safety analysis. All patients gave informed consent to study participation before enrollment. Each participant provides written informed consent before undergoing any study-related procedure. Patients were informed about their serological data before the completion of tests on work performances; they were not informed about their virological condition.

\section{Patients}

Among outpatients of our department 387 patients (age 25-65 years) who had never received a diagnosis of HCV patients, a total of 144 patients with chronic hepatitis C (62 women and 82 men) were consecutively enrolled in the study between January 2010 and December 2014 (Table 1). The patients underwent treatment with Peg-IFN-a 2b + RBV for 12 months. Eligibility criteria were a history of no previous treatment for $\mathrm{HCV}$ infection age of 25 years or older, weight of 50 to $100 \mathrm{Kg}$, chronic infection with $\mathrm{HCV}$ genotype 1 and plasma HCV RNA level of $10.000 \mathrm{IU} / \mathrm{ml}$ or greater. Exclusion criteria were liver disease of other cause positivity tests for serum hepatitis B surface antigen, positive test for serum HIV antibodies, negativity for HCV antibodies, alcoholic liver disease (daily alcohol consumptions $>20 \mathrm{~g} /$ day), and diabetes. The presence of other causes of hepatopathy, decompensated cirrhosis, pregnancy, and known contraindications for Peg-IFN-a or RBV therapy such as hemoglobinopathies, cardiopathy, hemocromatosis, diabetes mellitus, autoimmune diseases, major depression or other severe psychiatric pathological conditions, every active illicit treatment, and any drug that might influence serum lipid levels within the last 12 months were considered causes for ruling out. Patients undergoing treatment were prospectively asked to complete questionnaires before, during, and after treatment and follow up. Patients were excluded from the questionnaire protocol if they were not able to read or speak Italian. All patients were treated with Peg-IFN- $\alpha$ $2 \mathrm{~b}$ at dose $1.5 \mathrm{mg} / \mathrm{kg}$ per week, plus ribavirin (RBV) 
Table 1 Demographic, clinical, histological and virological characteristics of patients at baseline

\begin{tabular}{|c|c|}
\hline Parameter & $\begin{array}{l}\text { Patients treated with } \\
\text { Peg-IFNa + RBV }\end{array}$ \\
\hline N & 144 \\
\hline Mean age (years) & $43.8 \pm 7.8$ \\
\hline $\operatorname{Sex}(M / F)$ & $82 / 62$ \\
\hline Systolic blood pressure (SBP) mmHg & $132.6 \pm 10.8$ \\
\hline Diastolic Blood Pressure (DBP) mmHG & $81.8 \pm 6.7$ \\
\hline Heart Rate (HR) beats/min & $81.4 \pm 6.6$ \\
\hline HCV exposure time (years) & $5.64 \pm 6.8$ \\
\hline BMI $\left(\mathrm{kg} / \mathrm{m}^{2}\right)$ & $25.8 \pm 4.8$ \\
\hline \multicolumn{2}{|l|}{ Route of transmission of HCV (No of patients) } \\
\hline Blood transfusion & 86 \\
\hline Intravenous drug abuse & 26 \\
\hline Occupational & 12 \\
\hline Unknown & 20 \\
\hline \multicolumn{2}{|l|}{ HCV genotype } \\
\hline $1 \mathrm{a}$ & 9 \\
\hline $1 b$ & 125 \\
\hline Blue collars (manual labourers) & 50 \\
\hline White collars (non manual/office labourers) & 94 \\
\hline \multicolumn{2}{|l|}{ Laboratory parameters } \\
\hline Plasma glucose (mmol/l) (normal 3.9-6.4) & $5.41 \pm 0.96$ \\
\hline AST (IU/I) (normal 15-50) & $162 \pm 38$ \\
\hline ALT (IU/I) (normal 15-50) & $171 \pm 44$ \\
\hline Viremia $\left(10^{6} \mathrm{IU} / \mathrm{ml}\right)$ & $5.04 \pm 3.12$ \\
\hline CRP (mg/dl) (normal <1.0) & $4.6 \pm 0.7$ \\
\hline HAI (histological activity index) & $10.1 \pm 3.6$ \\
\hline
\end{tabular}

$1200 \mathrm{mg}$ for 12 months. Patients were evaluated before treatment, 1 month, 6 and 12 months after the initiation of the therapy. A follow-up evaluation was performed 6 months after the end of the planned treatment (Fig. 1 Flowchart).

\section{Laboratory exams}

A complete routine chemistry including red cell count, hemoglobin, white cell count, platelets prothrombin time, fasting plasma glucose, insulin, C-reactive protein, blood urea nitrogen, serum creatinine, bilirubin, ALT, aspartate aminotransferase, alkaline phosphatase, $\gamma$ glutamil transpeptidase, and creatin phosphokinase levels was performed at every medical visit.

\section{Virological findings}

Anti-HCV antibodies were evaluated by using second generation enzyme-linked immunosorbent assay (Ortho-Diagnostic Systems, Raritan, NJ), and positive samples were confirmed by immunoblotting (RIBA; Chiron Corporation,

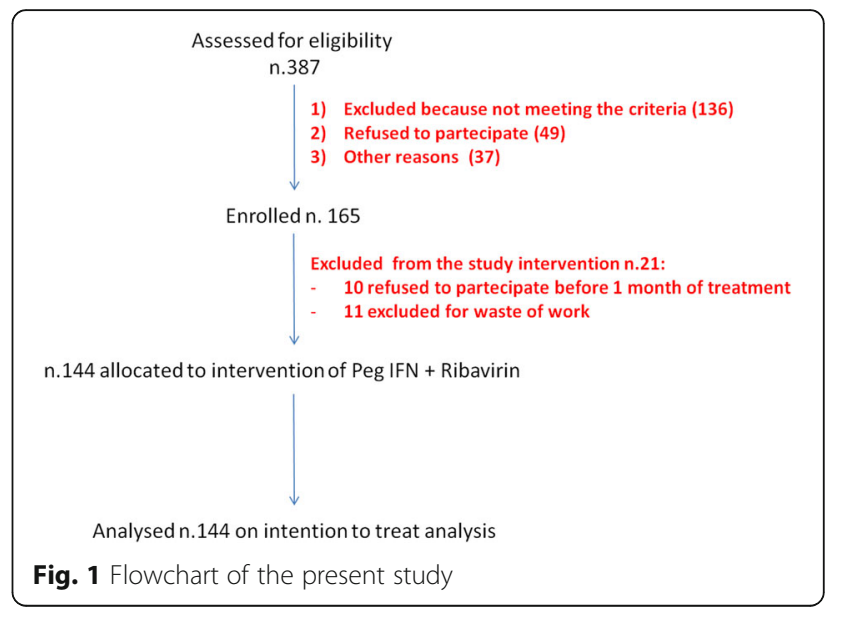

Emeryville, CA). For hepatitis B virus serological markers, we used kits (Abbott Laboratories, Chicago, IL). The presence of antibodies (antinuclear, antimitochondrial, antismooth muscle, and anti-liver-kidney-microsome) was evaluated by indirect immunofluorescence. Serum HCV RNA levels have been measured by standardized quantitative polymerase chain reaction (PCR) assay with a lower limit of detection of $<1,000 \mathrm{IU} / \mathrm{mL}$, using the Amplicor quantitative PCR system (Roche Diagnostic System Inc., Branchburg, NJ). Serum samples negative for HCV RNA were re-tested using a more sensitive standardized qualitative PCR assay with a lower limit of detection of about 100 $\mathrm{IU} / \mathrm{mL}$ to confirm HCV-RNA disappearance. HCV genotypes and subtypes were identified through a modification of the specific line probe assay (Inno-LiPA system; Innogenetics NV, Zwijnaarde, Belgium) as described by Stuyver et al. [19]. Briefly, primers complementary to the conserved sequences of the 5 untranslated regions of the different $\mathrm{HCV}$ genotypes were used in the reverse transcriptionPCR. HCV RNA were extracted from patients' sera and amplified by reverse transcription-PCR with the incorporation of biotinylated deoxyuridine triphosphate. Oligonucleotide probes (16-mers) that were specific for the different $\mathrm{HCV}$ genotypes and subtypes were hybridized with the patient's amplified viral complementary DNA. Hybridization was detected with alkaline phosphatase labeled streptavidin and nitroblue tetrazolium/5-bromo-4chloro-3-indolyl phosphate chromagens. The HCV genotypes were designated according to the nomenclature proposed by Simmonds et al. [20].

\section{Histology}

Liver biopsy was realized 6 months before the initiation of therapy and 6 months after the end of treatment. It was obtained using a modified Menghini technique. The specimen was fixed in neutral formaldehyde $4 \%$ solution for routine histological processing and evaluation. The Knodell and 
Ishak Histological activity index (HAI) score was used to assess the histological grading of the disease [21].

\section{Work ability}

The work ability is a tool to record the work ability of employees. It aims at identifying, at an early stage, health risks of early retirement an counteracting them [22]. The questionnaire is aimed at: 1) the estimated current and future work ability; 2) diagnosed illness and the number of absenteeism days in the previous year; 3) the estimated sickness-related deterioration in the work performance; 4) mental ability reserves. However, the questions can also be answered with the help of others, for example works physicians during the work medical examination. The WA can be used for individual employees and groups of workers. The WA has been used and tested on many occasions; this tool is easy to use. The time involved for the questionnaire is between 10 and 15 minutes. The WAI evaluates current work ability compared with lifetime and in relation to the demands of the job, number of current diseases diagnosed by a physician, estimated work impairment due to diseases. Completion of the questionnaire results is a score which lies between 7 and 49. A high value indicates good work ability; a lower value in unsatisfactory or jeopardized work ability. Depending on the level of score it is recommended to maintain (score 44-49), support (score 37-43), improve (score 28-36) or reinstate (score 7-27) the work ability.

\section{Perceived work stress}

Perceived Work Stress is an important part of the overall job demands. If work stress is becoming too high, this may result in negative consequences for job performance, absenteeism, work ability. The perceived work stress questionnaire comprises six stress factors (boredom, lack of support, quantitative and qualitative overload, unsatisfactory prospects or salary and unsatisfactory physical working conditions) and scores on a five point scale $(1=$ no stress; 5 = high stress) [23].

\section{Efficacy and safety assessment}

All enrolled patients were included in the intention-totreat efficacy analysis, and patients who received at least one dose of IFN-a plus RBV were included in the safety analysis Data were analyzed by an "intention to treat" principle. The response to treatment was defined either on the basis of serum ALT levels or serological presence of HCV-RNA. Lasting of results was considered as ETR (end of treatment response) or SVR (sustained response viral over 6 months after the end of treatment). ETR was defined as normalization of serum ALT levels during therapy and at the end of therapy associated with absence of serum HCV-RNA at the end of therapy. A sustained response was considered when HCV-RNA absence and
ALT normalization had been registered at the end of therapy and during the 6-month follow up period. We considered as relapsers the patients who showed ETR followed by relapse throughout the follow up period. Patients with HCV-RNA detectable in the serum at the end of the treatment have been defined as non responders (NR).

Adverse events were assessed by interviews, laboratory, and clinical examinations during treatment. They were graded as mild, moderate, and severe on the basis of World Health Organization score [18]. The treatment was definitively stopped in the case of severe events, such as hematological toxicity, hepatic failure, and no compliance. In moderate and mild cases of adverse effects, a dose reduction of $50 \%$ was performed, until the resolution of the event when a full dose was restarted.

\section{Statistical analysis}

Data are presented as mean values and standard deviations. The baseline values of each Perceived Work Stress score and of Work Ability dimension were compared to these obtained at the end of months 1, 3, 6, 12 as well as at the end of the follow-up period. Was considered significant where lesser than 0.05 .

Demographic and laboratory data were compared using one-way ANOVA. Statistical Analysis System (SAS/STAT version 6.12; SAS Institute, Cary, NC USA).

\section{Results}

\section{Baseline characteristics}

Baseline demographic, clinical, histological and virological characteristics of patients at baseline are reported in Table 1 . The most frequent viral genotype in patients was $1 \mathrm{~b}(86 \%)$ and the main route of transmission of HCV was blood transfusion (73\%). The blue collars (manual labourers) included in the study were 50 (34\%) while white collars (non manual/office labourers) were 94 (65\%) (Table 1).

\section{Course of biohumoral effects before the treatment}

The difference of biohumoral tests at $t=0$ and 6,12 months and follow-up were investigated with analysis of variance and t-test for Equality of Means $(n=144)$.

AST, ALT and Viremia are decreased $(p<0.01)$ at 6 months, at 12 months, and at follow-up (Table 2).

The comparison before and after the treatment with ANOVA test shows a significant decrease $(p<0.01)$.

\section{Course of perceived work stress (PWS)}

After 1 month treatment with Peg-IFN and ribavirin, we observed significant increases $(p<0.001)$ in boredom, lack of support, quantitative and qualitative overload, unsatisfactory prospects or salary, unsatisfactory physical working conditions. After 6 months and after 12 months we observed an increase for significant $p<0.001$ compared to 
Table 2 Means and standard deviations of biohumoral characteristics of subjects at baseline, at 1 month, 6 months, 12 months and follow-up. Values are expressed as Mean (SD)

\begin{tabular}{lcllcc}
\hline & Before Treatment & After 1 month & After 6 months & After 12 months & Follow-up \\
\hline AST (IU/L) & $184.4 \pm 37.1$ & $180.2 \pm 35.6$ & $96.4 \pm 37.4^{* *}$ & $68.2 \pm 24.9^{* *}$ & $65.4 \pm 22.1^{* *}$ \\
ALT(IU/L) & $196.8 \pm 36.4$ & $185.4 \pm 36.2$ & $104.4 \pm 38.1^{* *}$ & $69.1 \pm 20.6^{* *}$ & $71.4 \pm 16.1^{* *}$ \\
BILIRUBIN (mmol/L) & $10.2 \pm 6.8$ & $10.2 \pm 6.4$ & $10.3 \pm 6.9$ & $10.1 \pm 6.4$ & $10.5 \pm 6.1$ \\
ALBUMIN $(\mathrm{g} / \mathrm{dL})$ & $4.0 \pm 0.7$ & $4.0 \pm 0.6$ & $4.1 \pm 0.7$ & $4.0 \pm 0.9$ & $4.2 \pm 0.5$ \\
VIREMIA $\left(10^{6} \mathrm{IU} / \mathrm{mL}\right)$ & $5.44 \pm 2.20$ & $5.22 \pm 2.19$ & $3.9 \pm 2.8^{* *}$ & $2.87 \pm 2.0^{* *}$ & $2.9 \pm 1.8^{* *}$ \\
HAI & $10.1 \pm 3.6$ & - & - & $7.8 \pm 2.9^{* *}$ & - \\
\hline
\end{tabular}

Comparison between baseline and after the treatment ${ }^{*} p<0.05{ }^{* *} p<0.01$

Boredorm

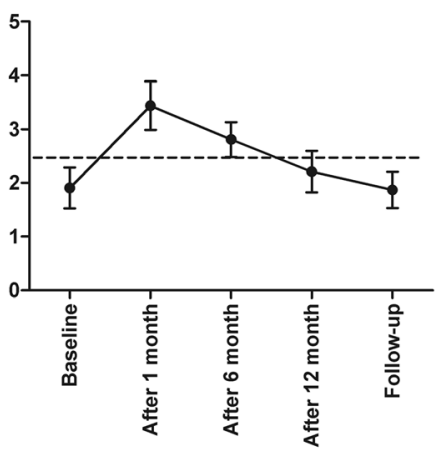

Quantitative Overload

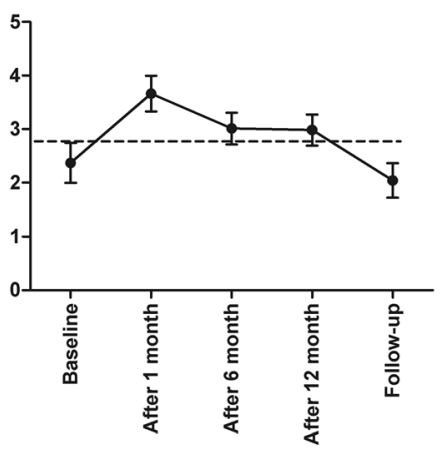

Unsatisfactory prospects or salary

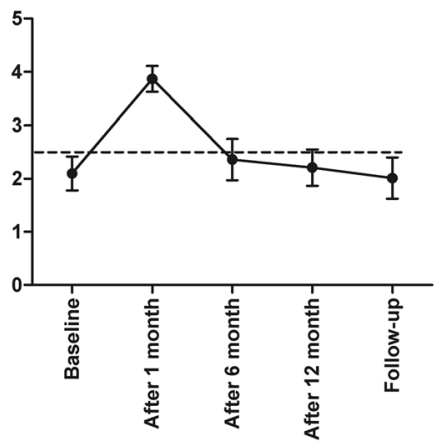

Lack of support

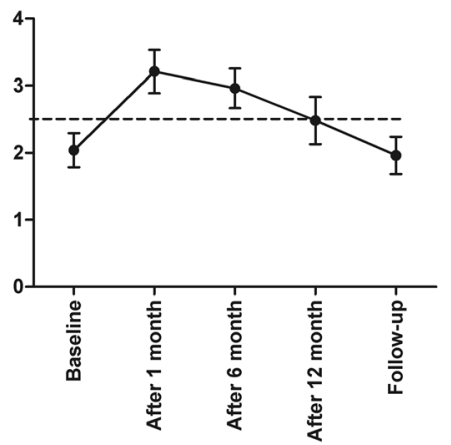

Qualitative Overload

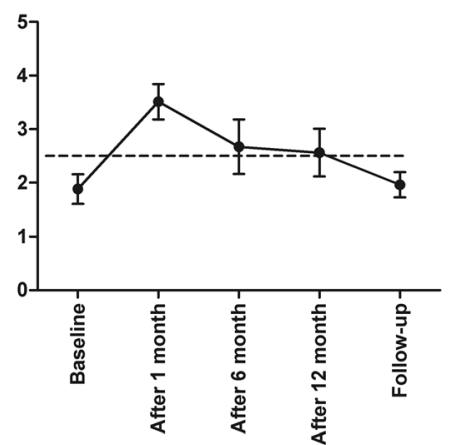

Unsatisfactory physical working conditions

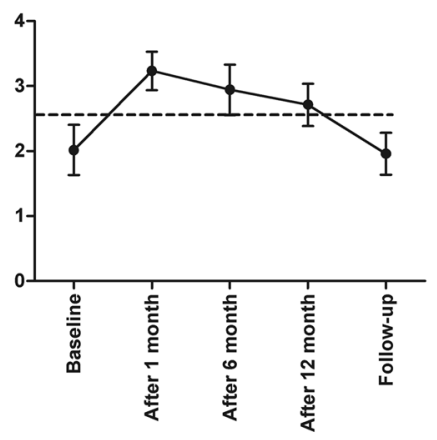

Fig. 2 Evaluation of Percieved Work Stress in the treatment of Peg-Interferon and Ribavirin 
baseline, but a decrease $p<0.05$ compared to 1 months. After 12 months, the increase were significant for all scores with the exception of the item "unsatisfactory prospects or salary", which was not significant. At follow up we observed significant differences in quantitative overload $(p<0.001)$. The comparison of patients' groups, before and after the treatment, with ANOVA test shows a decrease $(p<0.01)$ for all scores (Fig. 2).

\section{Comparison in work ability index}

With reference WA we observed a significant decrease $p<0.001$ after 1 month in all dimensions. After 6 months compared to baseline we observed a decrease in subjective work ability, in number of diseases, on work impairment, on prognosis of work ability and in mental resource.

After 12 months we observed significant decrease subjects work ability, in number of disease, in work impairment, in sick leave, in prognosis of work ability, in mental resources. The comparison of multiple groups, before and after the treatment, with ANOVA Test show a significant decrease $(p<0.001)$ for all scores (Fig. 3).

\section{Comparison between patients according to the response treatment in PWS}

The comparison between pretreatment patients and ETR patients show a significant decrease $(p<0.01)$ for boredom, lack of support, quantitative overload, qualitative overload, unsatisfactory prospects or salary, unsatisfactory physical working conditions. The comparison between sustained responders and pre-treated patients show a significant decrease in boredom $(p<0.01)$, lack support, quantitative overload, qualitative overload, unsatisfactory prospects or salary, unsatisfactory physical working conditions. No significant differences were observed in boredom, in quantitative overload and in unsatisfactory physical working conditions between non responders and pretreated patients, while in lack of support, in qualitative overload and in unsatisfactory of salary, we observed a significant increase $(p<0.05)$.

In comparison with relapsers and pretreated patients we observed no difference in boredom $(p<0.05)$ and in unsatisfactory working condition and significant difference $(p<$ $0.05)$ in quantitative prospects of salary and $p<0.01$ in both lack of support and in qualitative overload. (Table 3 ).

\section{Comparison between patients according to the response treatment in WA}

ETR patients compared with pretreated patients show a significant $p<0.05$ in subjective work ability, in work ability in relations to demands, in work impairment, in prognosis of work ability and in mental resources. No differences were observed in number of disease and in sick leave patients. Sustained responder compared with pretreated patients

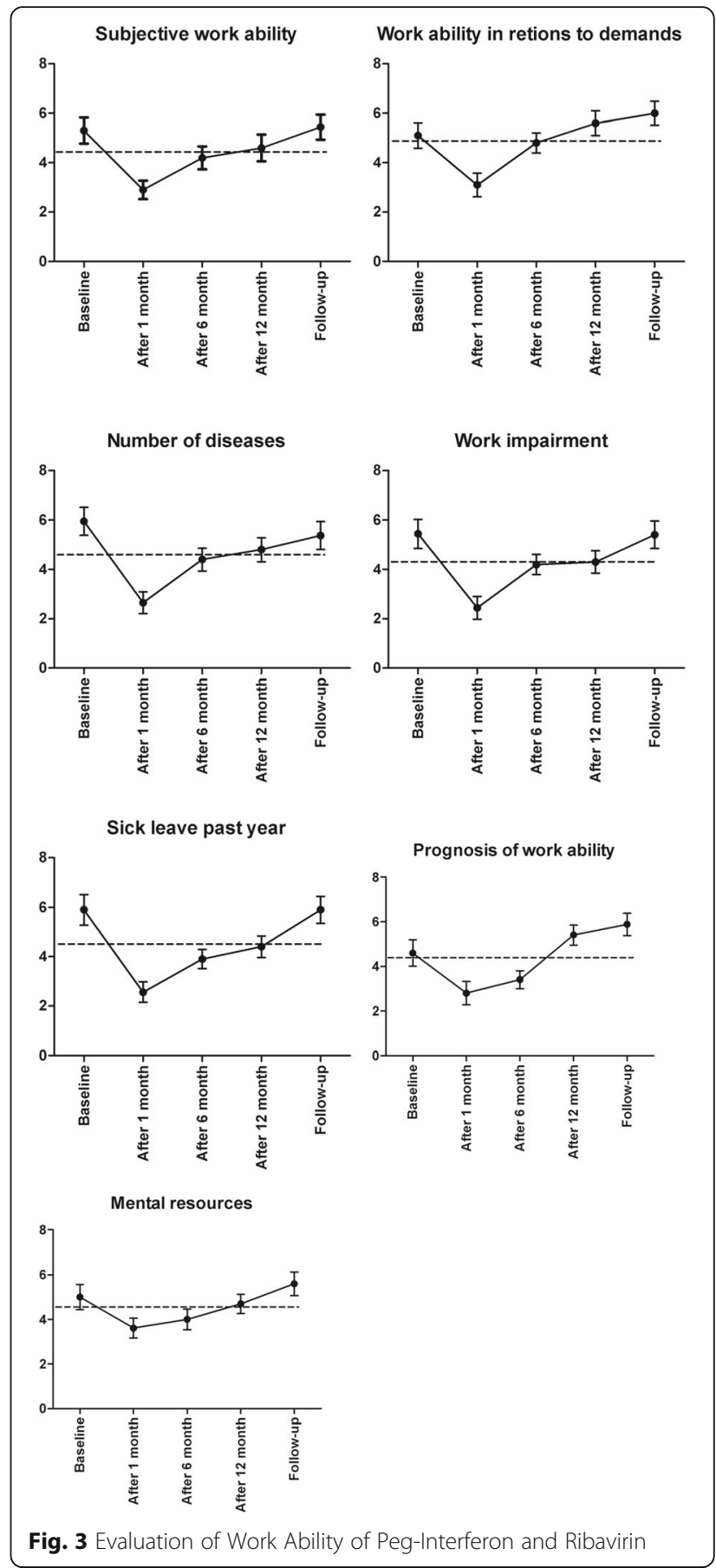

show a significant difference $p<0.01$ in subjective work ability, in work ability in relations to demands, in work impairment, in prognosis of work ability and in mental resources; $(p<0.05)$ in number of diseases and sick leave.

We observed no differences with pretreated patients in non responders and in relapsers patients regarding all dimensions (Table 4). 
Table 3 Comparison between patients according to the response treatment on PWS

\begin{tabular}{llllll}
\hline Peg-IFN a + RBV $(n=144)$ & \multicolumn{1}{l}{} & & \\
\hline & $\begin{array}{l}\text { Pretreatment } \\
(n=144)\end{array}$ & $\begin{array}{l}\text { ETR } \\
(n=65)\end{array}$ & $\begin{array}{l}\text { Sustained Responders } \\
(n=36)\end{array}$ & $\begin{array}{l}\text { Non Responders } \\
(n=50)\end{array}$ & $\begin{array}{l}\text { Relapsers } \\
(n=29)\end{array}$ \\
\hline Boredom & $1.94 \pm 0.61$ & $1.44 \pm 0.56^{* *}$ & $0.90 \pm 0.37^{* *}$ & $1.88 \pm 0.62$ & $1.98 \pm 0.47$ \\
Lack of support & $2.04 \pm 0.44$ & $1.87 \pm 0.67^{*}$ & $1.84 \pm 0.62^{*}$ & $2.22 \pm 0.61^{*}$ & $2.44 \pm 0.5^{* *}$ \\
Quantitative Overload & $2.37 \pm 0.65$ & $2.04 \pm 0.56^{* *}$ & $1.87 \pm 0.56^{* *}$ & $2.44 \pm 0.61$ & $2.56 \pm 0.5$ \\
Qualitative Overload & $1.88 \pm 0.48$ & $1.56 \pm 0.61^{* *}$ & $1.61 \pm 0.56^{*}$ & $2.01 \pm 0.56$ & $2.22 \pm 0.41^{* *}$ \\
Unsatisfactory prospects or salary & $2.10 \pm 0.55$ & $1.96 \pm 0.48$ & $1.82 \pm 0.42^{*}$ & $2.44 \pm 0.51^{* *}$ & $2.21 \pm 0.58$ \\
Unsatisfactory physical working conditions & $2.02 \pm 0.67$ & $1.78 \pm 0.56^{*}$ & $1.56 \pm 0.50^{* *}$ & $2.12 \pm 0.56$ & $2.08 \pm 0.38$ \\
\hline
\end{tabular}

Comparison between Pretreatment and Responses ${ }^{*} p<0.05,{ }^{*} p<0.001$

\section{Adverse events}

No serious adverse events (World Health Organization grade 3 or 4) have been reported. 18 patients showed mild psychological disorders such as anxiety, malaise, irritability, and depression. Median hemoglobin concentration significantly fell during the first 3 months of treatment, remaining stable for 3 months, and returning to values similar to the baseline within 3 months after the end of the treatment. Noteworthy, a higher decrease of hemoglobin values was observed in the Peg-IFN plus RBV alone treatment. The patients treated with Peg-IFN plus RBV experienced a fall in median hemoglobin concentration from $13.4 \mathrm{~g} / \mathrm{dL}$ (range 11.1-14.1 g/dL) to 11.0 (range 10.6-14.0 g/dL) at the end of therapy. It has been observed a significant decrease in the white cell blood count. The platelet counts did not significantly change. Further, other side effects registered were anorexia $(15 \%)$, nausea (18\%), weight loss $(10 \%)$, headache (33\%), fatigue (51\%), myalgia (34\%), musculoskeletal pain (38\%), hypertriglyceridemia (41\%), hypercholesterolemia (32\%), and hyperglycemia (27\%). Most patients in this clinical trial had $64 \%$ of adherence to their medication dose and duration of therapy.

\section{Discussion}

The purpose of this study was to investigate changes in both work ability and perceived work stress during the treatment of HCV patients with Peg-IFN and ribavirin. The impact of the HCV infection and antiviral therapy has been investigated in several studies [10, 11, 13, 16, 17]. Various endogenous inflammatory cytokines and exogenous cytokine-associated to depression and anxiety has been correlated with specific risk factors that may allow for potential preventive interventions. Across multiple studies, exogenous administration of cytokines to humans can trigger depression symptoms. Administration of cytokines or activation of the innate immune system can induce a behavioral repertoire, termed "sickness behavior" that includes anhedonia, anorexia, sleep changes, and decreased social interaction [23]. In many illnesses cytokine levels are cross - sectionally associated with depression risk $[24,25]$.

One aspect of regaining a normal life is a high risk of the loss of work that is associated with lower quality of life, lower self-esteem and worse financial situations. Previous study has showed a significant burden of HCV infection on work productivity, use of healthcare resources and related costs, and health-related quality of life (HRQL) $[14,26,27]$. There is also much variation in estimates of the monetary cost of productivity impairments and resource utilization in $\mathrm{HCV}[28,29]$. In $\mathrm{HCV}$ patients treated with Peg-IFN and ribavirin, we observed a decrease in work ability, in activities and hobbies that are normally enjoyed, a decreased ability to focus, concentrate or make decisions, an increase in perceived work stress (Fig. 4). In our study almost all dimensions of the WPS increased significantly $(p<0.001)$ after 1 month therapy. Because

Table 4 Comparison between patients according to the response treatment on WAI

\begin{tabular}{|c|c|c|c|c|c|}
\hline Dimensions & Pretreatment & ETR & Sustained responders & Non responders & Relapsers \\
\hline Subjective work ability & $5.30 \pm 0.91$ & $6.08 \pm 0.87^{*}$ & $6.78 \pm 0.96^{* *}$ & $5.34 \pm 0.81$ & $5.36 \pm 0.78$ \\
\hline Work ability in relations to demands & $5.10 \pm 0.88$ & $6.16 \pm 0.84^{*}$ & $6.70 \pm 0.87^{* *}$ & $5.25 \pm 0.87$ & $5.44 \pm 0.81$ \\
\hline Number of diseases & $5.95 \pm 0.98$ & $6.04 \pm 0.87$ & $6.44 \pm 0.81^{*}$ & $5.91 \pm 0.80$ & $5.68 \pm 0.84$ \\
\hline Work impairment & $5.44 \pm 1.02$ & $6.21 \pm 0.84^{*}$ & $6.81 \pm 0.82^{* *}$ & $5.45 \pm 0.87$ & $6.00 \pm 0.82$ \\
\hline Sick leave past year & $5.90 \pm 1.08$ & $5.81 \pm 0.87^{*}$ & $6.72 \pm 0.84^{*}$ & $5.84 \pm 0.88$ & $5.9 \pm 0.87$ \\
\hline Prognosis of work ability & $4.60 \pm 1.02$ & $6.28 \pm 0.91^{* *}$ & $6.41 \pm 0.87^{* *}$ & $4.71 \pm 0.96$ & $4.74 \pm 0.84$ \\
\hline Mental resources & $5.00 \pm 0.97$ & $5.94 \pm 0.81$ & $6.87 \pm 0.81^{* *}$ & $5.08 \pm 0.84$ & $5.10 \pm 0.88$ \\
\hline
\end{tabular}

Comparison between Pretreatment and Responses ${ }^{*} p<0.05,{ }^{* *} p<0.001$ 


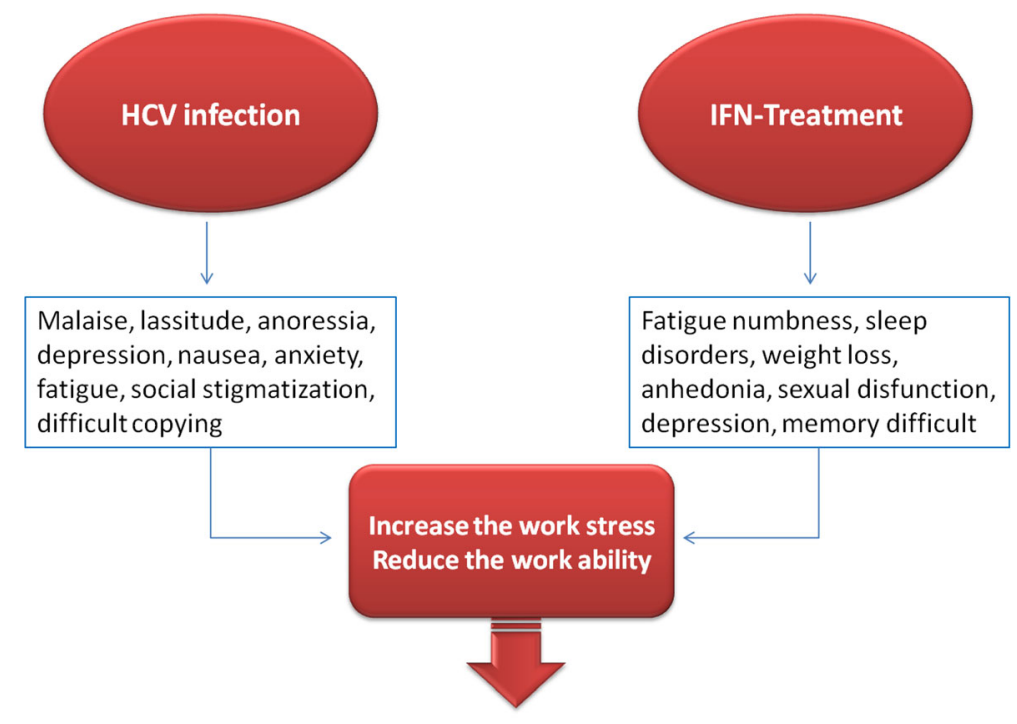

Job performance reduction

Fig. 4 This figure summarize the results of the present study

patients develop depression and anxiety during the first month of IFN- $\alpha$ treatment, this clinical model has been useful in prospectively examining various risk factors for developing depression and fatigue. At follow up we observed improvements of prospects and on working conditions and work ability. The decrease of work ability index, during treatment, may be due to more side effects of therapy [27]. Increased inflammatory cytokines production and particularly interferon (IFN- $\alpha$ ) manifest neuropsychiatric complication such as cognitive decline and psychomotor disturbance and often depression and fatigue [28]. There is a dose-response relationship between interferonalpha administration and depression with a gradual return to baseline mood after discontinuation [2934].

In our study both the decline of WAI and the increase of PWS ware similar for blue and white collar workers. This evidence indicates that workers involved in physically demanding jobs need positive physical exercise to stay at an average level. In white collar workers the most important changes in mental functions are related to the weakening of precision and the speed of perception.

Nausea, somnolence, fuzzy-thinking, weight loss, weakness, fatigue, itching are just a few of the common symptoms that may interfere with a person work, school, social activity and sense of well-being [31]. Debilitating physical states requiring high cost treatments, often in slow income patient populations, represents a burden on the health care system $[29,30]$.

The present study showed that workers affected by $\mathrm{HCV}$, treated with peg-IFN $\alpha 2 \mathrm{~b}$ plus Ribavirin, had an increase in WPS and productivity loss, and a decrease in work ability after 1 month treatment. In previous studies we observed that treatment with Peg-IFN and Ribavirin shows on increase in depression or irritable mood, in mental and physical fatigue severity, a decrease in attention, concentration and in memory activity $[16,17]$. The decrease of PWS in SVR and in ETR is associated with a reduction in both anxiety and depression status. Successful eradication of HCV leads to a significant improvement of work ability, indicating that the perceived work stress caused by potentially reversible. The combination of IFN and ribavirin no longer represents the therapeutic standard of care, at least for difficult to cure $\mathrm{HCV}$ infected patients of genotype $1 \mathrm{~b}$.

The impact of interferon may be comparable with other stressful life events and chronic diseases, like diabetes. Establishing the causes of reduction of work performance and productivity in patients with chronic infection is difficult, but the IFN treatment may be help to explain the consequence of chronic inflammation and such viral infection itself is an important factor contributing to reduce work performance (Fig. 4). The chronic inflammation is believed to signal the brain and to give rise to neurovegetative symptoms, such as malaise and among others psychiatric symptoms, such as depression and concentration difficulties.

\section{Conclusion}

Factors that may precipitate inflammation and influence the development of depression include medical illness, psychosocial stress, and sleep disturbance. Viral and bacterial infection may involve malaise, lassitude, fatigue, 
chills, numbness, aches of muscle, joint and body, headaches, insomnia, and depression cytokine induced are all symptoms associated to both work ability reduction and increase perceived work stress. Chronic exposure to elevated inflammatory cytokines, persistent alterations in neurotransmitter function and behavior can lead to the development neuropsychiatric dysfunction [35-39]. The loss of work performance increases with infection and with IFN treatment. Behavioral responses to cytokines can benefit an organism by promoting conservation of energy and allocation of resources to combat infection or recovery from injury along with behaviors that may elicit care giving from others $[40,41]$.

However it is important to talk with family and friends before starting treatment so they can understand and be supportive if need to cancel or adjust plans.

The new treatments with telaprevir and boceprevir have resulted in a higher rate of SVR, but the new interferonfree treatment has replaced these antiviral agents. The expanding treatment and the access to the highly effective cure of all HCV patients not only may improve the clinical outcomes but also patient-reported outcomes such as health-related quality of life and work productivity, resulting in comprehensive benefit to patients and the society [42].

Sustained responders had significant improvements is their job performance, reaching levels of WAI and decrease of PWS.

Our observational study population has an important limitation due to ethical reasons: our study design have considered patients treated with IFN and Ribavirin in absence of a non-treated group control. The absence of a non-treated group control does not consent us to understand whether the WAI and PWS differences exist because of the treatment or the chronic infection itself. However, our study suggests that the therapy with IFN and Ribavirin has a negative impact on the first month of treatment on job performance, but in the following months, the treatment reduce side effects, viral burden, and improve biochemical values. Moreover, the better tolerance to IFN and Ribavirin reduce PWS and improve WAI. Significant differences between pre-treated, responders, relapsers and non responders does not allow us to have a definitive answer to the question: "does the WAI and PWS depends on IFN and Ribavirin treatment or HCV infection?". However these data suggest that the therapeutic response on virus infection improve the job performance and reduce PWS.

Also the changes on work performance were linked to changes in clinical markers of chronic hepatitis C (ALT levels and viral burden). The greatest benefits were achieved by patients who had improvements.

Caution should be used in interpreting these results and extrapolating them to the $\mathrm{HCV}$ patients undergoing evaluation and therapy.
The pattern of changes seen across responders, nonresponders and relapsers group suggest that patients' awareness of their response to therapy cannot explain all the observed job performance change.

Successful antiviral therapy in associated with clinically meaningful, significant improvements in job performance.

\begin{abstract}
Abbreviations
ALT: Alanine transaminase; AST: Aspartate transaminase; BMI: Body mass index; CRP: C-reactive proteine; DBP: Diastolic blood pressure; ETR: End treatment response; HAl: Histological activity index; HCV: Hepatitis C Virus; HR: Heart rate; IFN: Interferon; MANOVA: Multivariate analysis of variance; N: Numbers; NR: Non responders; NS: Non significant; Peg-IFN-a or Peg-IFN-a 2b: Pegylated-Interferon-alfa 2beta; PWS: Perceived on work stress;

RBV: Ribavirin; SBP: Systolic blood pressure; SVR: Sustained viral response; WA: Work ability; WAl: Work ability index
\end{abstract}

\section{Acknowledgements}

The study was supported by MIUR.

Funding

This trial was supported by a grant from the Ministero dell'Università e Ricerca Scientifica e Tecnologica (MIUR).

\section{Availability of data and materials}

All data generated or analysed during this study are included in this published article. The datasets during the current study is available from the corresponding author on reasonable request.

\section{Authors' contributions}

All authors contributed equally to the manuscript. All authors read and approved the final manuscript.

\section{Competing interests}

The authors declare that they have no competing interests.

\section{Consent for publication}

All subjects included in this study signed consent form to publish the data collected.

\section{Ethics approval and consent to participate}

This study was approved by Cannizzaro Hospital Ethics Committee. All sensitive data were collected and protected in respect of present privacy statements.

\section{Author details}

${ }^{1}$ Department of Biomedical and Biotechnological Sciences, School of Medicine, University of Catania, 95125 Catania, Italy. ${ }^{2}$ Research Center "The Great Senescence", University of Catania, Catania, Italy. ${ }^{3}$ Department of Clinical and Experimental Medicine, University of Catania, Catania, Italy. ${ }^{4}$ Department of Ophthalmology, University of Catania, Catania, Italy. ${ }^{5}$ Neurovisual Science Technology (NEST), Catania, Italy. ${ }^{6}$ Department of Occupational Medicine, Vittorio Emanuele Hospital, University of Catania, Catania 1-95100, Italy. 'Department of Clinical and Experimental Medicine, University of Messina, Messina, Italy. ${ }^{8}$ Centre of Physical Medicine and Rehabilitation, Vittorio Emanuele Hospital, Catania, Italy.

Received: 10 May 2016 Accepted: 23 December 2016 Published online: 21 February 2017

\section{References}

1. Scott Bowden D, Berzsenyi MD. Chronic hepatitis C virus infection: genotyping and its clinical role. Future Microbiol. 2006;1(1):103-12.

2. Rapisarda V, Loreto C, Malaguarnera M, Ardiri A, Proiti M, Rigano G, Frazzetto E, Ruggeri MI, Malaguarnera G, Bertino N, Malaguarnera M, Catania VE, Di Carlo I, Toro A, Bertino E, Mangano D, Bertino G. Hepatocellular carcinoma and the risk of occupational exposure.World. J Hepatol. 2016; 8(13):573-90. doi:10.4254/wjh.v8.i13.573.

3. Bertino G, Ardiri A, Proiti M, Rigano G, Frazzetto E, Demma S, Ruggeri MI, Scuderi L, Malaguarnera G, Bertino N, Rapisarda V, Di Carlo I, Toro A, Salomone F, 
Malaguarnera M, Bertino E, Malaguarnera M. Chronic hepatitis C: This and the new era of treatment. World J Hepatol. 2016;8(2):92-106. doi:10.4254/wjh.v8.i2.92.

4. Malaguarnera M, Motta M, Vacante M, Malaguarnera G, Caraci F, Nunnari G, Gagliano C, Greco C, Chisari G, Drago F, Bertino G. Silybin-vitamin Ephospholipids complex reduces liver fibrosis in patients with chronic hepatitis C treated with pegylated interferon a and ribavirin. Am J Transl Res. 2015;7(11): 2510-8. eCollection 2015.

5. Fleshner M. Stress-evoked sterile inflammation, danger associated molecular patterns (DAMPs), microbial associated molecular patterns (MAMPs) and the inflammasome. Brain Behav Immun. 2013;27(1):1-7.

6. Mintz J, Mintz LI, Arruda MJ, Hwang SS. Treatments of depression and the functional capacity to work. Arch Gen Psychiatry. 1992;49(10):761-8.

7. Rost K, Smith JL, Dickinson M. The effect of improving primary care depression management on employee absenteeism and productivity. A randomized trial. Med Care. 2004;42(12):1202-10.

8. Schoenbaum M, Unützer J, Sherbourne C, Duan N, Rubenstein LV, Miranda J, Meredith LS, Carney MF, Wells K. Cost-effectiveness of practice-initiated quality improvement for depression: results of a randomized controlled trial. JAMA. 2001;286(11):1325-30.

9. Dantzer R. Cytokine-induced sickness behaviour: a neuroimmune response to activation of innate immunity. Eur J Pharmacol. 2004;500(1-3):399-411.

10. Foster GR. Quality of life considerations for patients with chronic hepatitis C. J Viral Hepat. 2009;16(9):605-11.

11. El Khoury AC, Vietri J, Prajapati G. The burden of untreated hepatitis C virus infection: a US patients' perspective. Dig Dis Sci. 2012;57(11):2995-3003.

12. Spiegel BM, Younossi ZM, Hays RD, Revicki D, Robbins S, Kanwal F. Impact of hepatitis $C$ on health related quality of life: a systematic review and quantitative assessment. Hepatology. 2005;41(4):790-800.

13. Schaefer M, Capuron L, Friebe A, Diez-Quevedo C, Robaeys G, Neri S, Foster GR, Kautz A, Forton D, Pariante CM. Hepatitis C infection, antiviral treatment and mental health: a European expert consensus statement. J Hepatol. 2012;57(6):1379-90.

14. Malaguarnera G, Pennisi M, Gagliano C, Vacante M, Malaguarnera M, Salomone S, Drago F, Bertino G, Caraci F, Nunnari G, Malaguarnera M. Acetyl-L-carnitine supplementation during HCV therapy with pegylated interferon-a 2b plus ribavirin: effect on work performance. A Randomized Clin Trial Hepat Mon. 2014;14(5):e11608.

15. Malaguarnera M. Acetyl-L-carnitine in hepatic encephalopathy. Metab Brain Dis. 2013;28(2):193-9. doi:10.1007/s11011-013-9376-4. Review.

16. Cabrera-Pastor A, Malaguarnera M, Taoro-Gonzalez L, Llansola M, Felipo V. Extracellular cGMP modulates learning biphasically by modulating glycine receptors, CaMKII and glutamate-nitric oxide-cGMP pathway. Sci Rep. 2016; 6:33124. doi:10.1038/srep33124

17. Malaguarnera G, Bertino G, Chisari G, Motta M, Vecchio M, Vacante M, Caraci F, Greco C, Drago F, Nunnari G, Malaguarnera M. Silybin supplementation during HCV therapy with pegylated interferon-a plus ribavirin reduces depression and anxiety and increases work ability. BMC Psychiatry. 2016; 16(1):398.

18. World Medical Association declaration of Helsinki. Recommendations guiding physicians in biomedical research involving human subjects. JAMA. 1997;277(11):925-6.

19. Stuyver L, Wyseur A, van Arnhem W, Hernandez F, Maertens G. Secondgeneration line probe assay for hepatitis $C$ virus genotyping. J Clin Microbiol. 1996;34(9):2259-66.

20. Simmonds P, Alberti A, Alter HJ, Bonino F, Bradley DW, Brechot C, Brouwer JT, Chan SW, Chayama K, Chen DS, et al. A proposed system for the nomenclature of hepatitis C viral genotypes. Hepatology. 1994;19(5):1321-4.

21. Knodell RG, Ishak KG, Black WC, Chen TS, Craig R, Kaplowitz N, Kiernan TW, Wollman J. Formulation and application of a numerical scoring system for assessing histological activity in asymptomatic chronic active hepatitis. Hepatology. 1981;1(5):431-5.

22. Tuomi K, Ilmarinen J, Martikainen R, Aalto L, Klockars M. Aging, work, lifestyle and work ability among Finnish municipal workers in 1981-1992. Scand J Work Environ Health. 1997;23 Suppl 1:58-65.

23. Dantzer R, Kelley KW. Twenty years of research on cytokine-induced sickness behavior. Brain Behav Immun. 2007;21(2):153-60.

24. Frommer MS, Edye BV, Mandryk JA, Grammeno GL, Berry G, Ferguson DA. Systolic blood pressure in relation to occupation and perceived work stress. Scand J Work Environ Health. 1986;12(5):476-85.

25. Loftis JM, Wall JM, Linardatos E, Benvenga S, Hauser P. A quantitative assessment of depression and thyroid dysfunction secondary to interferon- alpha therapy in patients with hepatitis C. J Endocrinol Invest. 2004;27(7): RC16-20.

26. Lotrich FE. Major depression during interferon-alpha treatment: vulnerability and prevention. Dialogues Clin Neurosci. 2009;11(4):417-25.

27. Md DB, Wagner JS, Yuan Y, L'Italien G, Langley P, Ray Kim W. The impact of hepatitis $C$ on labor force participation, absenteeism, presenteeism and non-work activities. J Med Econ. 2011;14(2):253-61.

28. Su J, Brook RA, Kleinman NL, Corey-Lisle P. The impact of hepatitis C virus infection on work absence, productivity, and healthcare benefit costs. Hepatology. 2010;52(2):436-42.

29. McCombs JS, Yuan Y, Shin J, Saab S. Economic burden associated with patients diagnosed with hepatitis C. Clin Ther. 2011;33(9):1268-80.

30. Neff GW, Duncan CW, Schiff ER. The current economic burden of cirrhosis. Gastroenterol Hepatol (N Y). 2011;7(10):661-71.

31. Horikawa N, Yamazaki T, Izumi N, Uchihara M. Incidence and clinical course of major depression in patients with chronic hepatitis type $\mathrm{C}$ undergoing interferonalpha therapy: a prospective study. Gen Hosp Psychiatry. 2003;25(1):34-8.

32. Biesmans S, Meert TF, Bouwknecht JA, Acton PD, Davoodi N, De Haes P, Kuijlaars J, Langlois X, Matthews LJR, Ver Donck L, Hellings N, Nuydens R. Systemic Immune Activation Leads to Neuroinflammation and Sickness Behavior in Mice. Mediators Inflamm. 2013;2013:271359. doi:10.1155/2013/ 271359.

33. Bonaccorso S, Marino V, Biondi M, Grimaldi F, Ippoliti F, Maes M. Depression induced by treatment with interferon-alpha in patients affected by hepatitis C virus. J Affect Disord. 2002;72(3):237-41.

34. Malaguarnera G, Vacante M, Drago F, Bertino G, Motta M, Giordano M Malaguarnera M. Endozepine-4 levels are increased in hepatic coma. World J Gastroenterol. 2015;21(30):9103-10. doi:10.3748/wjg.v21.i30.9103.

35. Miller RJ, Jung H, Bhangoo SK, White FA. Cytokine and chemokine regulation of sensory neuron function. Handb Exp Pharmacol. 2009;194:417-49.

36. Malaguarnera M, Scuderi L, Ardiri A, Malaguarnera G, Bertino N, Ruggeri IM, Greco C, Ozyalcn E, Bertino E, Bertino G. Type II mixed cryoglobulinemia in patients with Hepatitis C Virus: Treatment with pegylated-interferon and Ribavirin. Acta Medica Mediterr. 2015;31(3):651-62.

37. Malaguarnera M, Vacante M, Giordano M, Motta M, Bertino G, Pennisi M, Neri S, Malaguarnera M, Li Volti G, Galvano F. L-carnitine supplementation improves hematological pattern in patients affected by HCV treated with Peg interferona 2b plus ribavirin. World J Gastroenterol. 2011;17(39):4414-20.

38. Malaguarnera G, Catania VE, Francaviglia A, Malaguarnera M, Drago F, Motta M, Latteri S. Lipoprotein(a) in patients with hepatocellular carcinoma and portal vein thrombosis. Aging Clin Exp Res. 2016. doi:10.1007/s40520-0160653-z.

39. Malaguarnera M, Cristaldi E, Romano G, Malaguarnera L. Autoimmunity in the elderly: Implications for cancer. J Cancer Res Ther. 2012;8(4):520-7.

40. Malaguarnera M, Vacante M, Bertino G, Neri S, Malaguarnera M, Gargante MP, Motta M, Lupo L, Chisari G, Bruno CM, Pennisi G, Bella R. The supplementation of acetyl-L-carnitine decreases fatigue and increases quality of life in patients with hepatitis $C$ treated with pegylated interferona 2b plus ribavirin. J Interferon Cytokine Res. 2011;31(9):653-9.

41. Lotrich FE, Albusaysi S, Ferrell RE. Brain-derived neurotrophic factor serum levels and genotype: association with depression during interferon-a treatment. Neuropsychopharmacology. 2013;38(6):985-95.

42. Younossi ZM, Stepanova M, Zeuzem S, Dusheiko G, Esteban R, Hezode C, Reesink HW, Weiland O, Nader F, Hunt SL. Patient-reported outcomes assessment in chronic hepatitis $C$ treated with sofosbuvir and ribavirin: the VALENCE study. J Hepatol. 2014;61(2):228-34. doi:10.1016/j.jhep.2014.04.003. Epub 2014 Apr 5. 